\title{
Optimization of Technological Parameters for Preparation of Geopolymers Fabricated with Pulverized Fly Ash
}

\author{
Baomin Wang ${ }^{1 *}$, Chengcheng Fan $^{1}$, Yi Qi ${ }^{2}$ \\ 1. School of Civil Engineering, Faculty of Infrastructure Engineering, Dalian University of Technology, Dalian \\ 116024, China \\ 2. Dalian Teda Environmental Protection Co. LTD, Dalian 116024, China \\ E-mail:wangbm@dlut.edu.cn
}

Received: 29 July 2020; Accepted: 26 August 2020; Available online: 5 October 2020

\begin{abstract}
Geopolymer is widely considered as an important direction for the comprehensive utilization of fly ash with its production increasing sharply year by year. The effect of mixing proportion including $\mathrm{SiO}_{2} / \mathrm{Al}_{2} \mathrm{O}_{3}$ molar ratio, $\mathrm{Na}_{2} \mathrm{O} / \mathrm{SiO}_{2}$ molar ratio and water-solid ratio on the performances of geopolymer fabricated with pulverized fly ash with a median particle size of $3.3 \mu \mathrm{m}$ was investigated by an orthogonal test in this work, and the optimum preparation technics were also obtained. Results indicated that the compressive strength of geopolymer reached the maximum of $61.0 \mathrm{MPa}$ when $\mathrm{SiO}_{2} / \mathrm{Al}_{2} \mathrm{O}_{3}$ molar ratio was $3.3, \mathrm{Na}_{2} \mathrm{O} / \mathrm{SiO}_{2}$ molar ratio was 0.11 and the W/S ratio was 0.30 under the optimum preparation technics of aging time of $3 \mathrm{~h}$, mixing time of 3 min and curing at $80^{\circ} \mathrm{C}$ for 24h. Overall, $\mathrm{Na}_{2} \mathrm{O} / \mathrm{SiO}_{2}$ molar ratio played the most important role on the compressive strength of geopolymer, but $\mathrm{SiO}_{2} / \mathrm{Al}_{2} \mathrm{O}_{3}$ molar ratio had a minimal impact. FTIR spectrum demonstrated that the sample with the optimum proportion exhibited a more complex asymmetric stretching vibration peak, which indicated that there were more activated silicon/aluminum monomers and dimers in fly ash depolumerized and repolymerized and tetrahedral phase transitions, and then geopolymer paste with denser microstructure was formed.
\end{abstract}

Keywords: Geopolymer; Orthogonal test; Compressive strength; Microstructure.

\section{Introduction}

Coal fly ash, as the main solid waste produced by coal-fired power plants, was generated with a significant increase year by year. But poor comprehensive utilization resulted in the bulk storage of fly ash, which had posed a serious threat to the ecological environment and human health $[1,2]$. Therefore, it has become the issue of essential importance to be solved urgently to utilize fly ash in large-scale.

Nowadays, geopolymer has become an important choice for the comprehensive utilization of fly ash, and it is also an effective way to turn waste into treasure and develop new cleaner production [3,4]. Compared to the common cement, geopolymer is a collection of excellent performance including high strength, low hydration heat, energy saving, low-carbon environment, good durability and encapsulation [5-8]. And geopolymer has been widely regarded as the most promising alternative to cement in the future [9].

Activated silicon/aluminum substance existed in fly ash could be dissolved out in a strong alkali solution, and formed tetrahedral clusters with silicon-oxygen and aluminum-oxygen group, then formed a three-dimensional network compact amorphous structure by means of sharing of all oxygen atoms. Activated silicon and aluminum are the important components in structure of geopolymer, and categories of the structure phases in geopolymer mainly depend on $\mathrm{SiO}_{2} / \mathrm{Al}_{2} \mathrm{O}_{3}$ molar ratio. In detail, structure of geopolymer are polysialate (PS), polysialatesiloxo(PSS), polysialate-disiloxo(PSDS) when $\mathrm{SiO}_{2} / \mathrm{Al}_{2} \mathrm{O}_{3}$ molar ratio is 1, 2 and 3,repectively. And these three structures depend on the properties of geopolyer. So lots of studies were undertaken about effect of $\mathrm{SiO}_{2} / \mathrm{Al}_{2} \mathrm{O}_{3}$ molar ratio variations on the mechanical strength, structure and microtopography of geopolymer. In general, performance of geopolymer can be improved by increasing the $\mathrm{SiO}_{2} / \mathrm{Al}_{2} \mathrm{O}_{3}$ molar ratio in a certain range, but its performance will be adversely affected beyond this range. Rowles [10] investigated the properties of geopolymer with a $\mathrm{SiO}_{2} / \mathrm{Al}_{2} \mathrm{O}_{3}$ molar ratio range from 1 to 3 , and concluded that the maximum compressive strength of geopolymer would be realized when Si:Al:Na was 2.5:1:1.29, and the geopolymer at a $\mathrm{SiO}_{2} / \mathrm{Al}_{2} \mathrm{O}_{3}$ molar ratio of 1.5 would exhibited a heterogeneity and less compact than that at a $\mathrm{SiO}_{2} / \mathrm{Al}_{2} \mathrm{O}_{3}$ molar ratio of 2.5. Silva et al. [11] investigated the characteristics and microstructure of the geopolymer when $\mathrm{SiO}_{2} / \mathrm{Al}_{2} \mathrm{O}_{3}$ molar ratio ranged from 2.5 to 5.01 and $\mathrm{Na}_{2} \mathrm{O} / \mathrm{SiO}_{2}$ molar ratio ranged from 0.6 to 1.7 , and results showed that crystalline phase transformations were prone to occurred at a $\mathrm{SiO}_{2} / \mathrm{Al}_{2} \mathrm{O}_{3}$ molar ratios lower or higher than 3.8 and a higher $\mathrm{Na}_{2} \mathrm{O}$ content. Study from Provis et al. [12] has proved it and found that the reaction rates decreased with increasing the 
$\mathrm{SiO}_{2} / \mathrm{Al}_{2} \mathrm{O}_{3}$ molar ratio and lead to a longer setting time. Yan et al. [13] conducted a comparative study of high$\mathrm{Al}_{2} \mathrm{O}_{3}$ and low- $\mathrm{Al}_{2} \mathrm{O}_{3}$ fly ash based-geopolymers, and found that geopolymers modified with high- $\mathrm{Al}_{2} \mathrm{O}_{3}$ fly ash possess superior performance than that of low- $\mathrm{Al}_{2} \mathrm{O}_{3}$ fly ash modified samples in terms of compressive strength and microstructure. Duxon et al [14] came to the conclusion that the maximum compressive strength of metakaolin-based geopolymer would realize at a $\mathrm{SiO}_{2} / \mathrm{Al}_{2} \mathrm{O}_{3}$ molar ratio was 1.9. But Zhang et al [15] maximum compressive strength of metakaolin-based geopolymer would reach up to $34.9 \mathrm{MPa}$ when $\mathrm{SiO}_{2} / \mathrm{Al}_{2} \mathrm{O}_{3}$ molar ratio was 5.5 .

Similarly, the $\mathrm{Na}_{2} \mathrm{O} / \mathrm{SiO}_{2}$ molar ratio also contributed a lot to the performance development of geopolymer. Gao et al. [16] found that optimum performance and more compact structure of geopolymer could be reached at $\mathrm{Na}_{2} \mathrm{O} / \mathrm{SiO}_{2}$ molar ratio of 1.5 , and performance degradation would be occurred with the further increase of $\mathrm{Na}_{2} \mathrm{O} / \mathrm{SiO}_{2}$ molar ratio. Alkali activator at an appropriate concentration is beneficial to the dissolution and geopolymerization reaction of silicon/aluminum monomers. And Duxon et al. [17] went further to explain the effect of $\mathrm{Na}_{2} \mathrm{O} / \mathrm{SiO}_{2}$ molar ratio on condensation polymerization of geopolymer by means of nuclear magnetic resonance. This was consistent with the research from Criado. Duxon et al. [18]. They also found that Si content would increase the viscosity of the geopolymer paste and be not conducive to the polymerization reaction. Thus, we can draw a conclusion that the amount of activated silicon/aluminum monomers in the raw materials played a key role in the performance and microstructure of mortar. There are lots of methods on excitation of raw material active substances. In addition to the excitation of the alkali-activator, mechanical grinding is a widely way by increasing its specific surface area and crystal defects, meanwhile activated silicon/aluminum monomers in the finer raw materials were more conducive to dissolve and take geopolymerization reaction.

Therefore, geopolymer samples were well manufactured with pulverized fly ash in the laboratory with the sodium silicate as alkali-activator. And effects of the $\mathrm{SiO}_{2} / \mathrm{Al}_{2} \mathrm{O}_{3}$ molar ratio, $\mathrm{Na}_{2} \mathrm{O} / \mathrm{SiO}_{2}$ molar ratio and watersolid ratio on mechanical strength of geopolymers were conducted in this work by an orthogonal test. Following up on this basis, the optimum mixing proportion was obtained, and the preparation technics including aging time, stirring time, thermal curing time and temperature was also investigated with the control variable experiment. Meanwhile, X-ray powder diffraction (XRD), thermogravimetric analysis (TGA), Fourier transform infrared spectroscopy (FTIR) and scanning electron microscope (SEM) were also employed to investigate the geopolymerization mechanism and microstructural features during hydration process. The results obtained would provide some theoretical guidance and technical support for promoting the utilization of fly ash and engineering application of geopolymer.

\section{Formatting paper}

\subsection{Characterization of materials}

Pulverized fly ash with a median particle size of $3.3 \mu \mathrm{m}$ vided by Huaneng power plant was used as the main raw material for geopolymer. The main chemical composition of fly ash was obtained by S6 JAGUAR X-ray fluorescence (XRF), as shown in Table 1. And Fig.1 gave the particles size distribution of pulverized fly ash. In order to stimulate the pozzolanic activity of fly ash, commercially available sodium hydroxide (Tianjin Comio Chemical Reagent Co. Ltd, China) and sodium silicate obtained from the Gulf group (modulus $n=\mathrm{SiO}_{2} / \mathrm{Na}_{2} \mathrm{O}=3.3$, Baume degree $=40$, containing $8.3 \% \mathrm{Na}_{2} \mathrm{O}$ and $26.5 \% \mathrm{SiO}_{2}$ ) were also used in this work. And the alkali activators were formulated by dissolving the granular sodium hydroxide of analytical grade and the sodium silicate. It should be noted that the sodium silicate modulus was adjusted by the ratio of sodium hydroxide to sodium silicate.

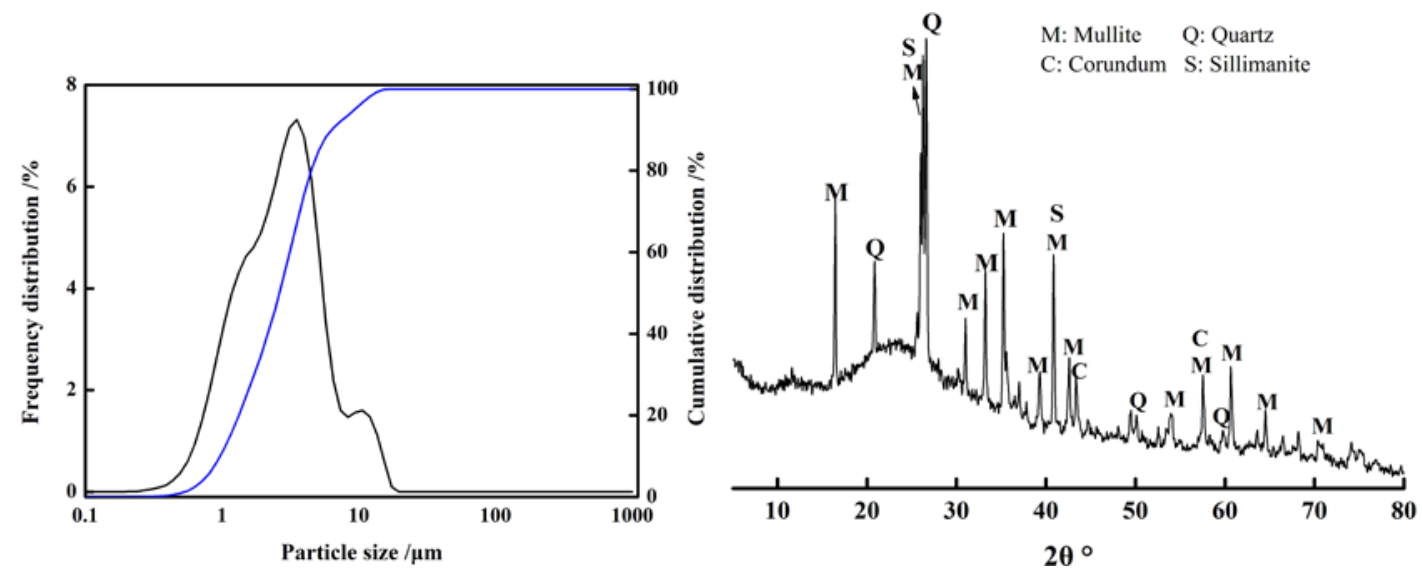

Fig.1. Particles size distribution and XRD pattern of pulverized fly ash 
Table 1. Chemical composition of fly ash from XRF analysis (\%)

\begin{tabular}{cccccccc}
\hline $\mathrm{SiO}_{2}$ & $\mathrm{Al}_{2} \mathrm{O}_{3}$ & $\mathrm{Fe}_{2} \mathrm{O}_{3}$ & $\mathrm{CaO}$ & $\mathrm{TiO}_{2}$ & $\mathrm{~K}_{2} \mathrm{O}$ & $\mathrm{MgO}$ & Other \\
\hline 48.67 & 29.16 & 8.98 & 4.73 & 2.75 & 2.66 & 0.74 & 2.31 \\
\hline
\end{tabular}

\subsection{Mixture proportion and preparation}

The geopolymer was activated with sodium hydroxide, sodium silicate and heat in this work. Fly ash powder was used in this work for the synthesis of geopolymer in different experimental conditions in terms of $\mathrm{SiO}_{2} / \mathrm{Al}_{2} \mathrm{O}_{3}$ molar ratio, $\mathrm{Na}_{2} \mathrm{O} / \mathrm{SiO}_{2}$ molar ratio and water-solid (W/S) ratio. An orthogonal test design was adopted to evaluate the effect of different factors on the mechanical strength of fly ash-based geopolymer. The design factors and their values levels were listed in table 2. Then geopolymers mix proportions and preparation process were optimized on the basis of the orthogonal test. And effect of the natural aging time, curing temperature and duration on properties of geopolymer was also investigated.

Geopolymer samples were prepared with the proportions mentioned above. Then mixtures were cast into the molds with dimensions of $40 \mathrm{~mm} \times 40 \mathrm{~mm} \times 40 \mathrm{~mm}$, vibrated and compacted, then covered every mold surface with plastic film, and cured the samples in the oven at $65^{\circ} \mathrm{C}$ for $24 \mathrm{~h}$. After the hardened samples were demoulded and then cured in the cement maintainer at room temperature for pre-defined curing periods successively.

Table 2. Mix proportion of test factors and levels

\begin{tabular}{cccc}
\hline Level & $\mathrm{SiO}_{2} / \mathrm{Al}_{2} \mathrm{O}_{3}$ molar ratio $(\mathrm{A})$ & $\mathrm{Na}_{2} \mathrm{O} / \mathrm{SiO}_{2}$ molar ratio $(\mathrm{B})$ & W/S ratio (C) \\
\hline 1 & 3.2 & 0.09 & 0.30 \\
2 & 3.3 & 0.10 & 0.31 \\
3 & 3.4 & 0.11 & 0.32 \\
\hline
\end{tabular}

\subsection{Experiment methods}

According to GB/T17671-1999, a hydraulic servo pressure testing machine (WAW-300) was used to measure the compressive strength under $0.2 \mathrm{~mm} / \mathrm{s}$ cross-head speed conditions. For each paste, at least 3 samples were tested and the average values of these samples were considered as the final results.

A mineralogical analysis was conducted by D8 ADVANCE X-ray powder diffractometer (Bruker AXS Co., Germany) with $\mathrm{Cu} \mathrm{K} \alpha$ radiation $40 \mathrm{keV}$ and $40 \mathrm{~mA}$ in the scanning angular range $5^{\circ} \sim 80^{\circ}$ with a $1^{\circ}$ step size. TGA analysis was were determined by STARe TGA/DSC (Mettler Toledo Co., Switzerland) in the temperature range from $50^{\circ} \mathrm{C}$ to $800^{\circ} \mathrm{C}$ with a heat rate of $10^{\circ} \mathrm{C} / \mathrm{min}$ under a dry dynamic nitrogen atmosphere (gas flow of $50 \mathrm{ml} / \mathrm{min}$ ). EQUINOX-55 Fourier transform infrared spectrum (Bruker AXS Co., Germany) was recorded on a Perkin-Elmer spectrometer model using $\mathrm{KBr}$ as dispersant. And microstructure images of samples were collected by NOVA Nano scanning electron microscopy (Fei Co., America) with operating voltage of $3.0 \mathrm{kV}$ and operating current of $8 \mathrm{~A}$ in an vacuum environment.

\section{Results and discussion}

\subsection{Compressive strength}

$\mathrm{SiO}_{2} / \mathrm{Al}_{2} \mathrm{O}_{3}$ molar ratio, $\mathrm{Na}_{2} \mathrm{O} / \mathrm{SiO}_{2}$ molar ratio and the W/S ratio are the important factors affecting the workability and performance of geopolymer [19]. Table 3 listed the results of compressive strength and orthogonal test and range analysis. As observed in Table 3, the compressive strength at 3d of geopolymer reached 52.1 MPa, and the compressive strength of geopolymer increased with the increasing of curing time. The compressive strength at 3d, $7 \mathrm{~d}$ and $28 \mathrm{~d}$ of geopolymer reached the maximum when $\mathrm{SiO}_{2} / \mathrm{Al}_{2} \mathrm{O}_{3}$ molar ratio was $3.3, \mathrm{Na}_{2} \mathrm{O} / \mathrm{SiO}_{2}$ molar ratio was 0.11 and the W/S ratio was 0.30 .

Table 3. Compressive strength of fly ash-based geopolymer

\begin{tabular}{ccccccc}
\hline \multirow{2}{*}{ Code } & A & B & C & \multicolumn{3}{c}{ Compressive strength /MPa } \\
\cline { 5 - 6 } & 1 & 1 & 1 & 24.7 & $7 \mathrm{~d}$ & 30.2 \\
2 & 1 & 2 & 2 & 19.8 & 27.5 & 28.8 \\
3 & 1 & 3 & 3 & 31.7 & 25.8 & 36.2 \\
4 & 2 & 1 & 2 & 18.1 & 33.0 & 28.3 \\
5 & 2 & 2 & 3 & 22.9 & 23.2 & 39.9 \\
6 & 2 & 3 & 1 & 52.1 & 53.7 & 58.2 \\
7 & 3 & 1 & 3 & 16.2 & 19.3 & 21.2 \\
8 & 3 & 2 & 1 & 24.7 & 31.2 & 39.8 \\
9 & 3 & 3 & 2 & 23.7 & 26.7 & 49.9 \\
\hline
\end{tabular}


In general, fly ash can't react with water to form cement hardened paste. But the active components including active silica and activated alumina existed in fly ash can be dissolved and pozzolanic reaction occurred with aqueous alkali to form cementious paste [20-22]. Thus, properties of geopolymers mainly depended on the pozzolanic properties of fly ash and its activation degree [23]. In another words, $\mathrm{Na}_{2} \mathrm{O} / \mathrm{SiO}_{2}$ molar ratio indeed directly determined the mechanical properties of geopolymer. Table 4 listed the order of influence of factors, where $\mathrm{Ki}(\mathrm{i}=1,2,3)$ is a mean of test indicators corresponding to each level of the factor, and $\mathrm{R}$ is its range. $\mathrm{Na}_{2} \mathrm{O} / \mathrm{SiO}_{2}$ molar ratio played the most important role on the compressive strength of geopolymer, and $\mathrm{SiO}_{2} / \mathrm{Al}_{2} \mathrm{O}_{3}$ molar ratio had a minimal impact. If the activator concentration was too low, the excitation would be incomplete. But high $\mathrm{Na}_{2} \mathrm{O} / \mathrm{SiO}_{2}$ molar ratio would lead to rapid reaction rates, and early precipitation of some geopolymer gels would block potential formation of more amorphous gel and cause more unreated active components left in fly ash [24]. In addition, high $\mathrm{Na}_{2} \mathrm{O} / \mathrm{SiO}_{2}$ molar ratio would result in the efflorescence phenomenon. $\mathrm{SiO}_{2} / \mathrm{Al}_{2} \mathrm{O}_{3}$ molar ratio and W/S ratio were the key factors affecting the workability of geopolymer paste. During the experiment process, the sample paste was sticky when the $\mathrm{SiO}_{2} / \mathrm{Al}_{2} \mathrm{O}_{3}$ molar ratio was high, and the converse was also diluted.

Table 4. Compressive strength and test analysis of fly ash-based geopolymer

\begin{tabular}{|c|c|c|c|c|c|c|c|c|c|}
\hline Code & A & $\mathrm{B}$ & $\mathrm{C}$ & A & $\mathrm{B}$ & $\mathrm{C}$ & A & $\mathrm{B}$ & $\mathrm{C}$ \\
\hline K1 & 22.1 & 17.1 & 29.4 & 25.0 & 20.3 & 32.6 & 27.6 & 23.1 & 36.6 \\
\hline K2 & 26.9 & 19.5 & 17.9 & 30.9 & 25.1 & 21.9 & 36.0 & 31.4 & 31.0 \\
\hline K3 & 18.7 & 31.2 & 20.5 & 22.4 & 32.9 & 23.8 & 32.1 & 41.2 & 28.2 \\
\hline $\mathrm{R}$ & 24.6 & 42.2 & 34.7 & 25.4 & 37.8 & 26.4 & 11.6 & 54.2 & 25.1 \\
\hline Influence order & & $\mathrm{B}>\mathrm{C}>\mathrm{A}$ & & & $\mathrm{B}>\mathrm{C}>\mathrm{A}$ & & & $\mathrm{B}>\mathrm{C}>\mathrm{A}$ & \\
\hline Optimal design & & $\mathrm{B}_{3} \mathrm{C}_{1} \mathrm{~A}_{2}$ & & & $\mathrm{~B}_{3} \mathrm{C}_{1} \mathrm{~A}_{2}$ & & & $\mathrm{~B}_{3} \mathrm{C}_{1} \mathrm{~A}_{2}$ & \\
\hline Compressive strength & & $3 d$ & & & $7 \mathrm{~d}$ & & & 28d & \\
\hline
\end{tabular}

In order to make full use of the pozzolanic activity of fly ash and improve the properties of geopolymer, control variable method was also used in this work to study the effect of the preparation technics on the mechanical properties of gropolymer. As shown in Fig.2, the optimum mechanical properties of geopolymer was obtained with the aging time of $3 \mathrm{~h}$, mixing time of $3 \mathrm{~min}$, curing temperature of $80^{\circ} \mathrm{Cand}$ curing time of $24 \mathrm{~h}$. Fig. 1 proved that the properties of geopolymer would increase when the curing temperature increased from $20^{\circ} \mathrm{C} \sim 80^{\circ} \mathrm{C}$. It indicated that thermal curing temperature played an important role on the pozzolanic activity of fly ash. Meanwhile, the compressive strength of geopolymer would increase first and then reduced with the increase of curing time, and the maximum compressive strength of samles were realized at the curing time of 24h. It was because long time high temperature curing would destroy the structural water and amorphous phases in the geopolymer, and led to a reduction to the compressive strength. It was also consistent with the research results from Jaarsvelad[25]. It should be noted that the compressive strength of the samples cured at the temperature of $80^{\circ} \mathrm{C}$ was only $1.1 \%$ higher than that of the curing temperature of $60^{\circ} \mathrm{C}$. Taking the high energy consumption brought by hightemperature curing into account simultaneously, the optimum curing temperature of $65^{\circ} \mathrm{C}$ was chosen for the following study.

The characteristic of sodium silicate solution will affect the properties of geopolymer, and the aging time largely determined the properties of sodium silicate solutions [26]. Generally, a newly prepared sodium silicate solution was in a mesostable state because the depolymerization and polycondensation occurred simultaneously in sodium sodium silicate solution at this stage. It gradually tended to equilibrium with the increase of aging time [27]. As shown in Fig.2, when the aging time of sodium silicate solution exceeded 3h, there was a slight reduction in the compressive strength of geopolymern at first and then stabilized with increasing aging time. In addition, it not conducive to performance development when agitation process of the fly ash mixed with the sodium silicate solution lasted for long. Stirring for too long would destroy the three-dimensional mesh products of geopolymers in the initial stage, which led to poor properties of geopolymer.

Furthermore, the geopolymer prepared with pulverized fly ash exhibited a better performance than that prepared with unaltered fly ash on the whole [28]. This is because some changes on the properties and structures occurred during the pulverizing process of common fly ash. The dense surface shell structure of fly ash will be damaged under the mechanics effect, which will lead to some changes on structure and the performance of fly ash. On the one hand, the mechanical grinding caused more lattice defects of materials and some chemical bond fracture such as $\mathrm{Si}-\mathrm{O}$ and Al-O bonds, then released more active substances such as activated silica and activated alumina and active chemical groups, which is beneficial to improve the pozzolanic activity. On the other hand, the mechanical grinding effect can improve the chemical energy of fly ash particles and chemical instability, which leads to a higher chemical reactivity. 

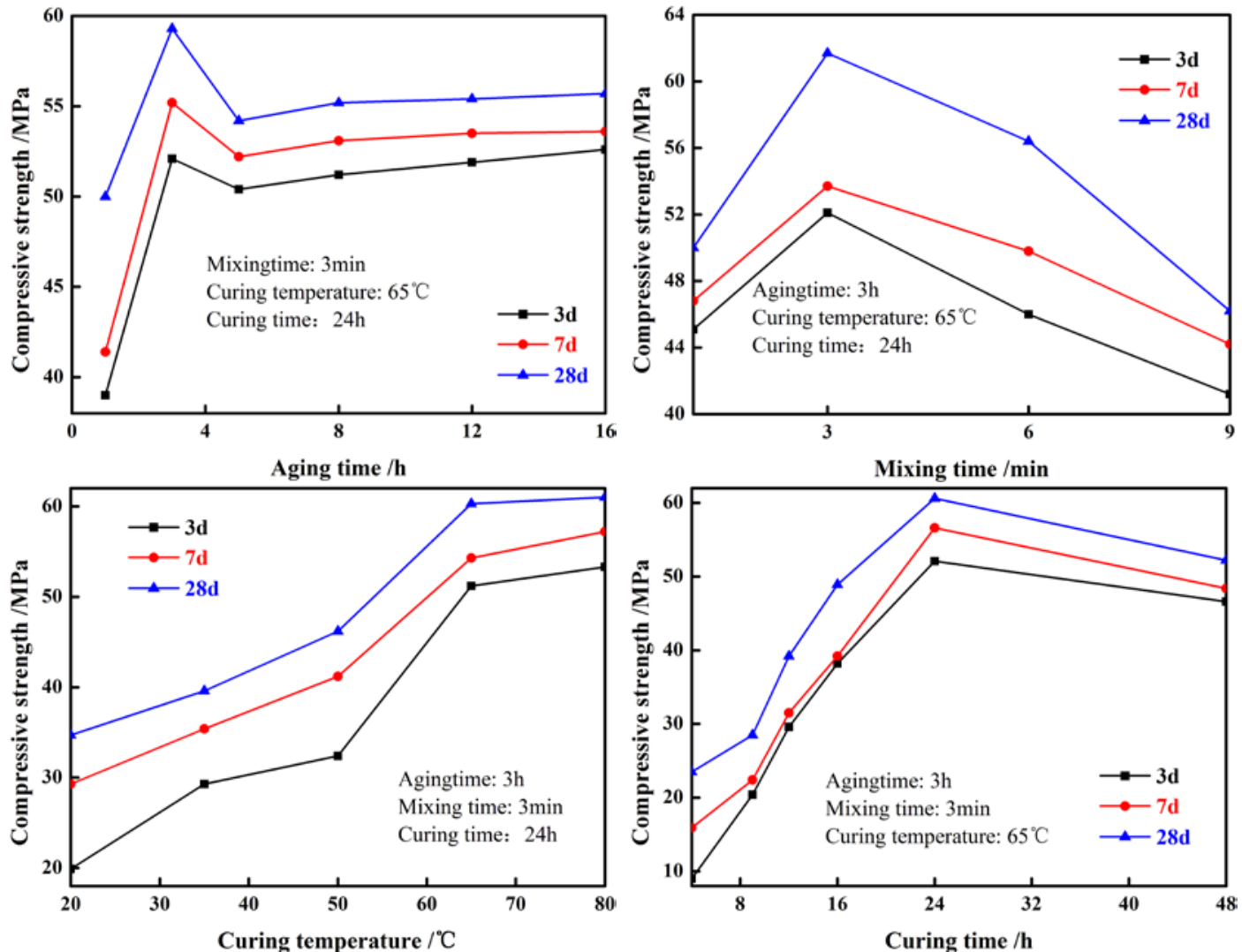

Fig. 2. Effect of preparation technics on properties of geopolymers

\subsection{XRD analysis}

Fig.3 showed the XRD patterns of geopolymers samples numbered No.6 and No.7. The broad humps appeared at $17^{\circ} \sim 40^{\circ}$ in the diffraction patterns were reported as amorphous geopolymer gels [29]. Different from fly ash as mentioned above, there was no diffraction peak of corundum detected in XRD patterns of geopolymers samples and some new sillimanite crystalline phases generated, which indicated the corundum crystalline minerals were involved in the geopolymerization reaction. Meanwhile, it can be found that some crystalline peaks of samples curing for 28d exhibited a slight downward trend in the intensities than that curing for 3d, which was indicating some of the crystalline phases were consumed gradually during the geopolymerization process with increasing time. Additionally, it should be noted that the main crystalline peaks of samples at different mixing proportions were about the same when $2 \theta$ ranged from $5^{\circ}$ to $80^{\circ}$, and there was no significant change in hydration products of geopolymer samples at different mixing proportions.

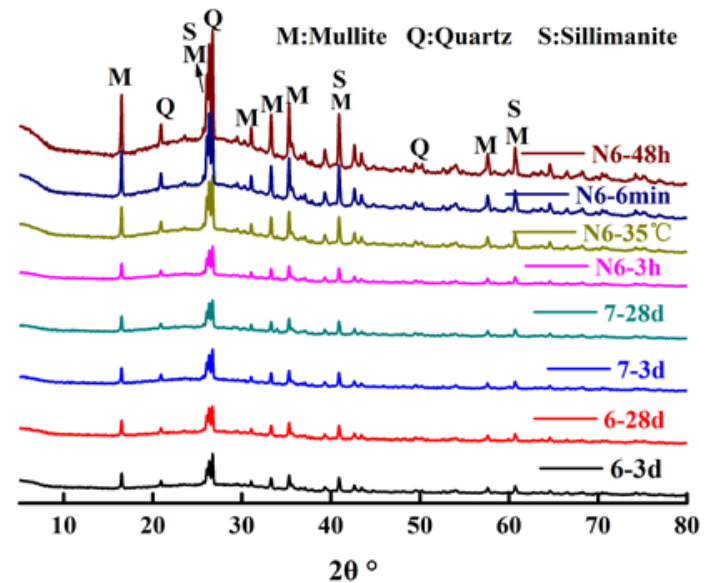

Fig. 3. XRD patterns of geopolymer samples 


\subsection{TGA/DTG analysis}

The TGA/DTG data analysis curves of the geopolymer samples were given in Fig.4. It indicated that the weight loss of the geopolymer samples was $6.2 \% \sim 7.7 \%$ in the temperature range of $50^{\circ} \mathrm{C} \sim 1000^{\circ} \mathrm{C}$. There was a major weight loss peak in samples appeared at $50 \sim 250^{\circ} \mathrm{C}$, which was attributed to the evaporation of bound water in geopolymeric gels (N-A-S-H). According to the weight loss curves, it can be found that the highest weight loss rate was realized in No.6 samples curing for 28d. It demonstrated that the most geopolymeric gels generated in No.6 samples, contributing to the highest strength, which was also consistent with the compressive strength results. The evaporation of both structural water and hydroxyl groups in hydration products were responsible for the weight loss in temperature range of $250 \sim 650^{\circ} \mathrm{C}$. And the weak weight loss peak occurred at the temperature range of $650 \sim 450^{\circ} \mathrm{C}$ was attributed to decomposition of carbonates. As shown in Fig.4, the weight loss of No.7 samples was much more than No.6. Considering the higher activator concentration used in No.7 samples, it manifested that higher activator concentration was easily to lead to the carbonization of geopolymer and was not conducive to the structural stability of geopolymers. Thus, it is of great significance to explore the appropriate mixing proportion and alkali activator for development of geopolymer.
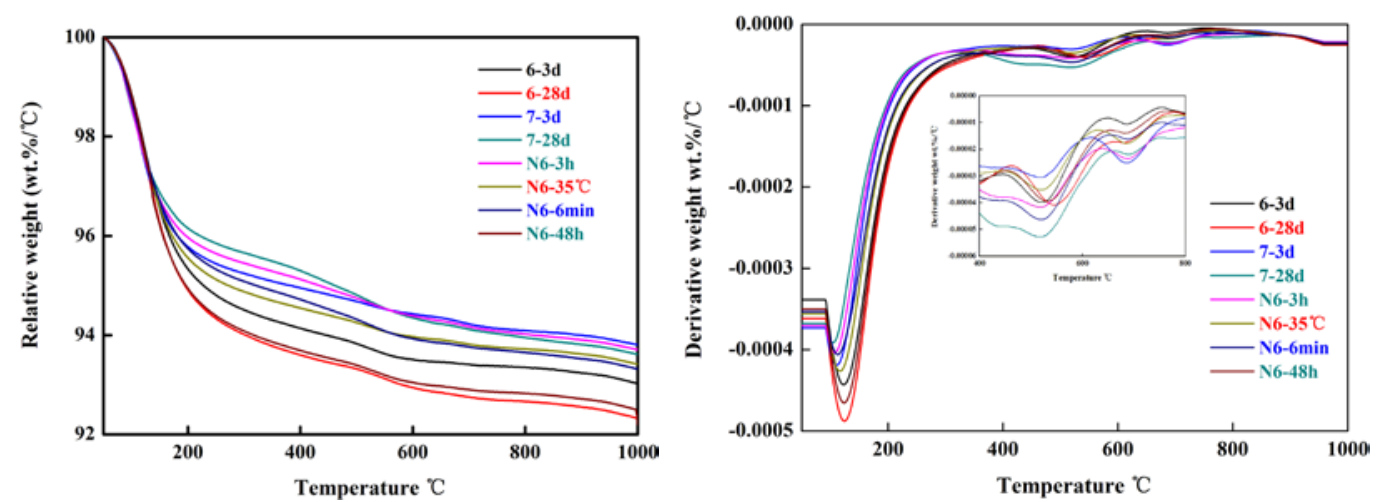

Fig. 4. TGA and DTG curves for geopolymer samples

\subsection{FTIR analysis}

FTIR was also employed to explore the molecular vibration modes and chemical bonds change of geopolymer. As displayed in Fig.5, the horizontal and vertical axis in FTIR spectra represented the wavenumber and infrared light transmittance, respectively.

The peak at $3470 \mathrm{~cm}^{-1}$ and $1650 \mathrm{~cm}^{-1}$ with absorption peak was the $\mathrm{O}-\mathrm{H}$ stretching vibration and $\mathrm{O}-\mathrm{H}$ bending vibration of water phase, respectively [30,31]. And the $\mathrm{H}-\mathrm{O}$ stretching vibration peak of samples curing for $3 \mathrm{~d}$ (at $3450 \mathrm{~cm}^{-1}$ or $3460 \mathrm{~cm}^{-1}$ ) was stronger than that of samples curing for $28 \mathrm{~d}$ and became to migrate towards 3460 $\mathrm{cm}^{-1}, 3470 \mathrm{~cm}^{-1}$. It demonstrated that free water reduced and converted into crystal water gradually with the increase of hydration time.

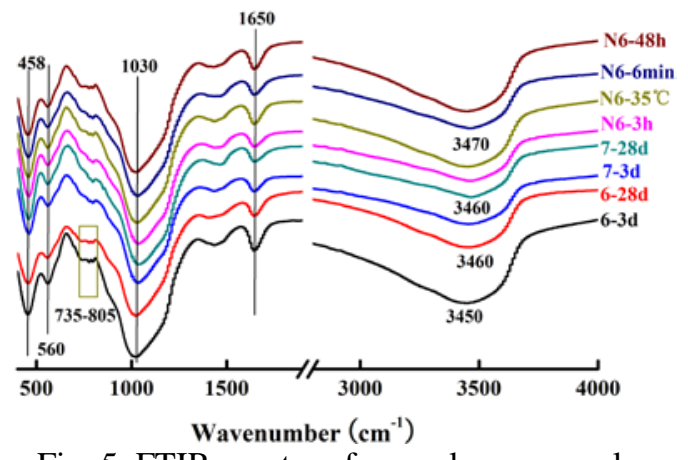

Fig. 5. FTIR spectra of geopolymer samples

The peaks at $800 \mathrm{~cm}^{-1}$ and $1030 \mathrm{~cm}^{-1}$ were the characteristic infrared peak of quadrature silicon, and correspond to asymmetric stretching vibration and symmetric stretching vibration of Si-O, respectively [32,33]. The peaks at 457-459 $\mathrm{cm}^{-1}$ were also correspond to the bending vibration of Al-O/Si-O [34]. And the weak symmetric stretching vibration of C-O appeared at $1410 \mathrm{~cm}^{-1}$ to $1470 \mathrm{~cm}^{-1}$.

Peaks ranging from $735 \mathrm{~cm}^{-1}$ to $805 \mathrm{~cm}^{-1}$ were the complex asymmetric stretching vibration of Si-O in siliconoxygen tetrahedron group of geopolymer [35]. It was speculation that asymmetric stretching vibration peak was split because of difference of chemical bond and chemical bond angle changes in Si-O-M during the geopolymerization process. Further to say, there were some phase transitions such like decomposition of silica and 
generation of new tetrahedral structure when Si was replaced by tetracoordinated $\mathrm{Al}$ [36]. In contrast to the sample No.7, the sample No.6 would exhibit a more complex asymmetric stretching vibration peak and the peak ranged from $735 \mathrm{~cm}^{-1}$ to $805 \mathrm{~cm}^{-1}$. It indicated that the geopolymerization reaction of raw material was more complete in sample No.6, and more tetrahedral phases were formed to a more compact structure, which was also in accordance with the results of compressive strength and SEM analysis.

\subsection{SEM analysis}

The morphology features of geopolymer samples were tested by SEM, as shown in Fig.6, and it should be noted that (a) (b) (c) is the SEM images of sample No.6, and (d) is the SEM image of sample No.7. It can be observed obviously from the Fig.6 that there were a large number of amorphous gels and some crystal phases generated. Compared to the sample No.6, the microstruture of sample No.7 was a little bit of loose and porous, and there were some unreacted fly ash left. It is because the activator concentration was too low to stimulate pozzolanic activity of fly ash completerly, and the generation of new silicoaluminate amorphous gels would be affected without sufficient active Si-Al phase monomers [37].

In the initial stage, fly ash powder dissolved and some particles size decreased with the chemical reaction with alkali activator. Meanwhile, alkali activator diffused into the hollow sphere structure of fly ash and reacted with the active silicon and active aluminum existed in fly ash to form some new crystalline materials such as mullite and stilbite. Take mullite for example, the crystals were elongated columns and radiating clusters and it penetrated through the sphere structure of fly ash, as shown in Fig.6(b). And fly ash was also geopolymerized with alkali activator to form some new silicoaluminate amorphous gels, which deposited and wrapped on the surface and interior surface of fly ash particles. Then the silicoaluminate amorphous gels were integrated with the fly ash sphere structure. Additionally, when there were some unreacted incompletely fly ash particles embedded in the amorphous substances, the hydration process of geopolymer would be retarded. Overall, alkali excitation process of fly ash covered the dissolution, diffusion and repolymerization of active silicon and aluminum, which was consistent with the reaction model of fly ash geopolymerization proposed by Fernandez-Jimenez in the previous research [25].
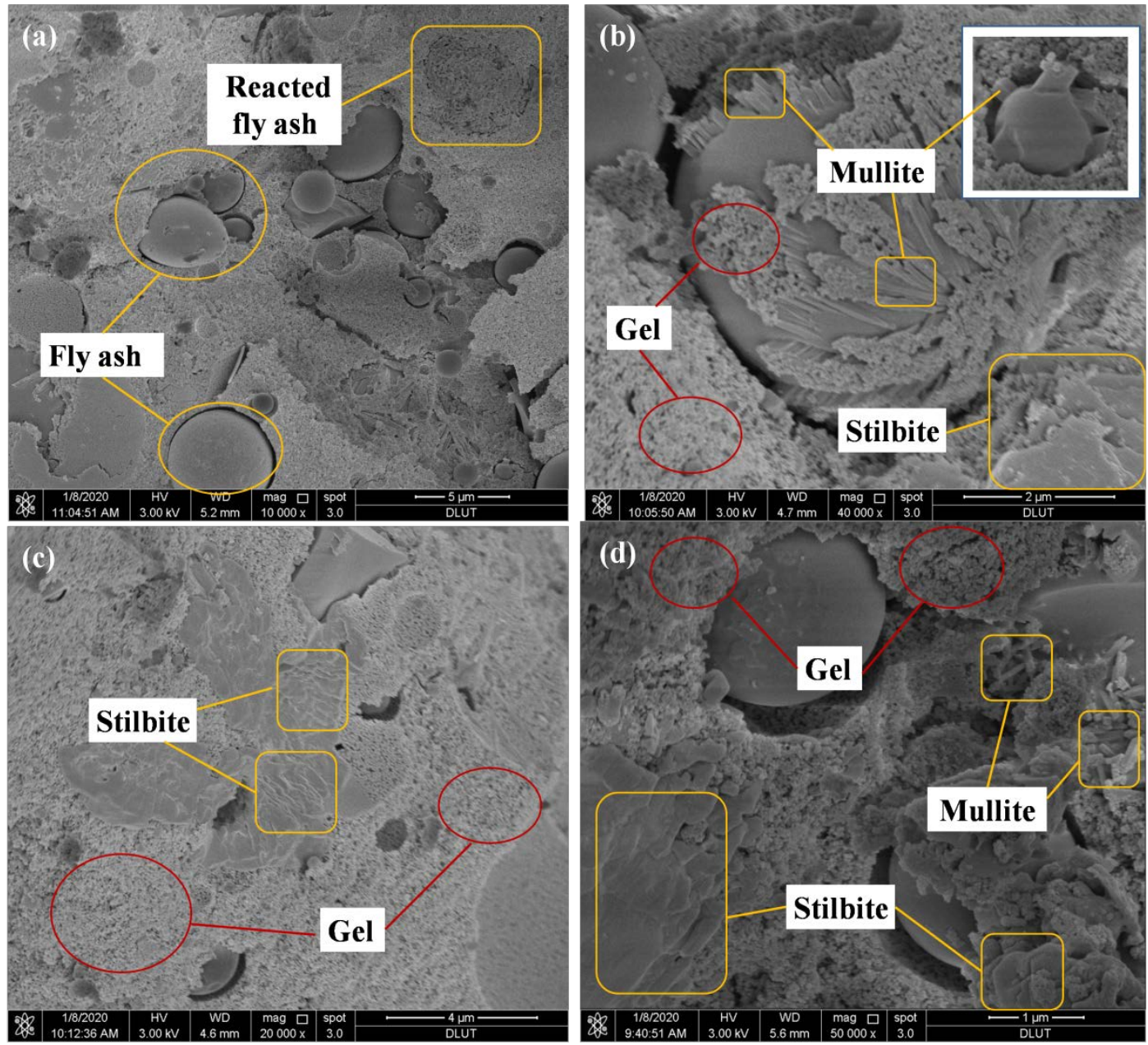

Fig. 6. SEM images of geopolymer samples 


\section{Conclusions}

Properties and structural characteristics of pulverized fly ash-based geopolymer obtained by alkali activation of fly ash have been investigated in this work. And the main conclusions of present work are as follows:

(1) The highest compressive strength of 58.2MPa was obtained using an aqueous solution of sodium silicate as an activator with $\mathrm{SiO}_{2} / \mathrm{Al}_{2} \mathrm{O}_{3}$ molar ratio of 3.3, $\mathrm{Na}_{2} \mathrm{O} / \mathrm{SiO}_{2}$ molar ratio of 0.11 and the W/S ratio of 0.30 .

(2) Orthogonal test results indicated that $\mathrm{Na}_{2} \mathrm{O} / \mathrm{SiO}_{2}$ molar ratio played the most important roles on mechanical performances of geopolymer, followed by water-solid ratio and $\mathrm{SiO}_{2} / \mathrm{Al}_{2} \mathrm{O}_{3}$ molar ratio.

(3) The optimum preparation technics of aging time of $3 \mathrm{~h}$, mixing time of $3 \mathrm{~min}$ and curing at $65^{\circ} \mathrm{C}$ for $24 \mathrm{~h}$ was adopted to prepare the geopolymer samples in consideration of energy conservation, and the compressive strength of samples would reach the maximum of 60.3MPa.

(4) Alkali activation process of fly ash covered the dissolution, diffusion and repolymerization of active silicon and aluminum, and some heterogeneous amorphous products and crystal phases were generated.

(5) FTIR and SEM analysis results demonstrated that there was more complete geopolymerization reaction occurred in samples with a high $\mathrm{SiO}_{2} / \mathrm{Na}_{2} \mathrm{O}$ molar ratio, and exhibited a more complicated asymmetric stretching vibration peak and denser structure, which significantly contributed to developement the mechanical properties of geopolymer.

\section{Acknowledgments}

This study was funded by the National Science Foundation of China (51878116), the Liaoning Province Key Project of Research and Development Plan (2020JH2/10100016) and Dalian Science and Technology Innovation Fund Project (2020JJ26SN060).

\section{References}

[1] Sharma AP, Tripathi BD. Magnetic mapping of fly-ash pollution and heavy metals from soil samples around a point source in a dry tropical environment. Environmental Monitoring \& Assessment. 2008; 138(1-3):31.

[2] Bandarra BS, Gomes LA, Pereira JL, et al. Assessment of hazardous property HP 14 using ecotoxicological tests: a case study of weathered coal fly ash. Environmental Science and Pollution Research. 2020; 27:2097220983.

[3] Supriadi W, Subaer, Bayuaji R, et al. The effect of $\mathrm{Pb}^{2+}$ and $\mathrm{Cd}^{2+}$ addition to mechanical properties of fly ash geopolymer paste. Materials Science Forum. 2016; 841:178-185.

[4] Temuujin J, Riessen AV, Mackenzie KJD. Preparation and characterisation of fly ash based geopolymer mortars. Construction and Building Materials. 2010; 24(10):1906-1910.

[5] Chindaprasirt P, Chareerat T, Sirivivatnanon V. Workability and strength of coarse high calcium fly ash geopolymer. Cement \& Concrete Composites. 2007; 29(3):224-229.

[6] Pan Z, Sanjayan JG, Rangan BV. An investigation of the mechanisms for strength gain or loss of geopolymer mortar after exposure to elevated temperature. Journal of Materials Science. 2009; 44(7):1873-1880.

[7] Li KL, Jiang LH, Cai YB. Investigation on heavy metal and radioactive metal solidification by geopolymer materials. Materials \& Structures. 2010; 233-241.

[8] Bakharev T. Durability of geopolymer materials in sodium and magnesium sulfate solutions. Cement \& Concrete Research. 2005;35(6):1233-1246.

[9] Zhao JW, Cui C, Ge YP, et al. Recent development of research on durability of geopolymer for civil structural applications. Bulletin of the Chinese Ceramic Society. 2016;35(9):2832-2840.

[10] Rowles M, Conor B. Chemical optimization of the compressive strength of aluminosilicate geopolymers synthesized by sodium silicate activation of metakaolinite. Journal of Materials Chemistry. 2003; 13(5):11611165.

[11] De Silva P, Sagoe-Crenstil K. Medium-term phase stability of $\mathrm{Na}_{2} \mathrm{O}-\mathrm{Al}_{2} \mathrm{O}_{3}-\mathrm{SiO}_{2}-\mathrm{H}_{2} \mathrm{O}$ geopolymer systems. Cement and Concrete Research. 2008; 38(6), 870-876.

[12] Duxson P, Provis JL, Lukey GC, et al. Understanding the relationship between geopolymer composition, microstructure and mechanical properties. Colloids and Surfaces A: Physicochemical and Engineering Aspects. 2005; 269(1-3): 47-58.

[13] Wei Zhou, Chunjie Yan, et al. A comparative study of high- and low- $\mathrm{Al}_{2} \mathrm{O}_{3}$ fly ash based-geopolymers: The role of mix proportion factors and curing temperature. Materials and Design. 2016; 95: 63-74.

[14] Duxson P, Provis JL, Lukey GC, Mallicoat SW, Kriven WM. Understanding the relationship between geopolymer composition, microstructure and mechanical properties. Colloids and Surface A Physicochemical and Engineering Aspects. 2005; 269(1-3):47-58.

[15] Zhang Y, Sun W, Li Z. Composition design and microstructrural characterization of calcined kaolin-based geopolymer cement. Applied Clay Science. 2010; 47(3):271-275. 
[16] Gao k, Lin K, Wang D, Hwang C, Shiu H, Chang Y, Cheng T. Effect of $\mathrm{SiO}_{2} / \mathrm{Na}_{2} \mathrm{O}$ molar ratio on mechanical properties and the microstructure of nano- $\mathrm{SiO}_{2}$ metakaolin-based geopolymers. Construction and Building Materials. 2014; 53(4):503-510.

[17] Criado M, Fernández-Jiménez A, Palomo A, et al. Effect of the $\mathrm{S} \mathrm{SiO}_{2} / \mathrm{Na}_{2} \mathrm{O}$ ratio on the alkali activation of fly ash. Part II: 29Si MAS-NMR Survey. Microporous and Mesoporous Materials. 2008; 109(1-3): 525-534.

[18] Duxson P, Fernández-Jiménez A, Provis JL, et al. Geopolymer technology: the current state of the art. Journal of materials science. 2007; 42(9): 2917-2933.

[19] Rashad AM, Zeedan SR, Hassan AA. Influence of the activator concentration of sodium silicate on the thermal properties of alkali-activated slag pastes. Construction and Building Materials. 2016; 102:811-820.

[20] Morsy MS, Alsayed SH, Al-Salloum Y, et al. Effect of sodium silicate to sodium hydroxide ratios on strength and microstructure of fly ash geopolymer binder. Arabian Journal for Science and Engineering. 2014; 39:4333-4339.

[21] Al-Kutti W, Nasir M, Johari MAM, et al. An overview and experimental study on hybrid binders containing date palm ash, fly ash, OPC and activator composites. Construction and Building Materials. 2018; 159:567577.

[22] Ishwarya G, Singh B, Deshwal S, Bhattacharyya S.K. Effect of sodium carbonate/sodium silicate activator on the rheology, geopolymerization and strength of fly ash/slag geopolymer pastes. Cement \& Concrete Composites. 2019; 97:226-238.

[23] Stellacci P, Liberti L, Notarnicola M, et al. Valorization of coal fly ash by mechano-chemical activation. Chemical Engineering Journal. 2009; 149(1-3):19-24.

[24] Lee WKW, Deventer JSJV. The effects of inorganic salt contamination on the strength and durability of geopolymers. Colloids \& Surfaces A Physicochemical \& Engineering Aspects. 2002; 211(2-3):115-126.

[25] Fernández-Jiménez A, et al. Microstructure development of alkali-activated fly ash cement: a descriptive model. Cement \& Concrete Research. 2005; 35(6):1204-1209.

[26] Emdadi Z, Asim N, Yarmo MA, et al. The study of $\mathrm{NaOH}$ and aging time effects on green geopolymer's compressive strength. Advances in Environmental Biology. 2016; 10(8):119-125.

[27] A Abdulkareem O, Al Bakri Abdullah MM, Kamarudin H, et al. The influence of curing periods on the compressive strength of fly ash-based geopolymer at different aging times. Advanced Materials Research. 2012; 479-481:512-516.

[28] Chindaprasirt P, Rattanasak U. Utilization of blended fluidized bed combustion (FBC) ash and pulverized coal combustion (PCC) fly ash in geopolymer. Waste Management. 2010; 30(4): 667-672.

[29] Yaseri S, Hajiaghaei G, Mohammadi F, et al. The role of synthesis parameters on the workability, setting and strength properties of binary binder based geopolymer paste. Construction and Building Materials. 2017; 157(30):534-545.

[30] Lin Y, Liao Y, et al. A study on co-pyrolysis of bagasse and sewage sludge using TG-FTIR and Py-GC/MS. Energy Conversion \& Management. 2017; 151:190-198.

[31] Chen Z, Li JS, Zhan BJ, et al. Compressive strength and microstructural properties of dry-mixed geopolymer pastes synthesized from GGBS and sewage sludge ash. Construction and Building Materials. 2018; 182(10):597-607.

[32] Liu Z, Wang J, Jiang Q, et al. A green route to sustainable alkali-activated materials by heat and chemical activation of lithium slag. Journal of Cleaner Production. 2019; 225(10):1184-1193.

[33] Wei Zhou, Chunjie Yan, Ping Duan, et al. A comparative study of high- and low $-\mathrm{Al}_{2} \mathrm{O}_{3}$ fly ash basedgeopolymers: The role of mix proportion factors and curing temperature. Materials \& Design. 2016; 95:6374.

[34] Sun Z, Vollpracht A. One year geopolymerisation of sodium silicate activated fly ash and metakaolin geopolymers. Cement \& Concrete Composites. 2018; 95:98-110.

[35] Yu P, Kirkpatrick RJ, Poe B, et al. Structure of calcium silicate hydrate (C-S-H): near-, mid-, and far-infrared spectroscopy. Journal of the American Ceramic Society. 2010; 82(3):742-748.

[36] Sha Dong, Pan Baofeng, Sun Yiren. A novel raw material for geopolymers: Coal-based synthetic natural gas slag. Journal of Cleaner Production. 2020; 262.

[37] Phetchuay C, Horpibulsuk S, Suksiripattanapong C, Chinkulkijniwat A, Arulrajah A, Disfani MM. Calcium carbide residue: Alkaline activator for clay-fly ash geopolymer. Construction and Building Materials. 2014; 69:285-294

(C) 2020 by the author(s). This work is licensed under a Creative Commons Attribution 4.0 International License (http://creativecommons.org/licenses/by/4.0/). Authors retain copyright of their work, with first publication rights granted to Tech Reviews Ltd. 